\title{
Altitudinal training sets of pollen rain - vegetation cover and modelled climate as a tool for the interpretation of paleoecological records
}

\author{
Roberta Pini $^{1 *}$, Federica Badino ${ }^{1}$, Michele Brunetti ${ }^{2}$, Elena Champvillair ${ }^{3}$, Giulia Furlanetto ${ }^{3}$, \\ Francesca Vallè ${ }^{3}$, Cesare Ravazzi ${ }^{1}$, Mattia De Amicis ${ }^{3}$
}

\begin{abstract}
${ }^{1} \mathrm{CNR}$ - Institute for the Dynamics of Environmental Processes (IDPA), Laboratory of Palynology and Palaeoecology, Piazza della Scienza 1, 20126 Milano (I); ${ }^{2} \mathrm{CNR}$ - Institute of Atmospheric Sciences and Climate (ISAC), via Piero Gobetti 101, 40129 Bologna (I); ${ }^{3}$ University of Milano-Bicocca, Dept. of Environmental and Earth Sciences, Piazza della Scienza 1, 20126 Milano (I)

*email: roberta.pini@idpa.cnr.it
\end{abstract}

Received: 20 April 2017/Accepted: 31 May 2017

\begin{abstract}
To improve our ability to reconstruct past environments and climate from fossil pollen records, modern proxy calibration studies along climatic and ecological gradients are needed. Here we present the first training set of modern pollen rain, vegetation, climate and terrain parameters developed along a 1700m-high transect in the western Italian Alps. The accurate knowledge on the relationships between these factors is essential for robust and sound reconstructions of past ecosystems based on microscopic plant remains.
\end{abstract}

Keywords: pollen dispersal, ecosystems reconstructions, ecological gradient, quantitative climate parameters

\section{Introduction}

Paleoecological records, including pollen, spores, algae and a wide range of microbiological particles, are a powerful tool to reconstruct the vegetation history of pertinent geographic areas and to disentangle the effects of climate variability and human impact on vegetation. Developing quantitative methods for ecosystem and paleoclimate reconstructions is a main challenge for paleoecology (Juggins \& Birks 2012) especially in mountain landscapes. Here, several basic questions are still to be addressed: 1) Can we provide reasonable estimates of species abundance based on their pollen percentages in sediments? 2) Can we account for the bias of long-distance transport of pollen by convective winds? 3) Are there different degrees of asso- ciation between parent plant and pollen occurrence, useful to infer the local presence/absence of species? 4) Can we derive quantitative estimates of past climate parameters using fossil pollen spectra?

\section{Study area}

We present here an altitudinal pollen-vegetation-climate training set built in the La Thuile Valley (western Italian Alps, Fig. 1). 


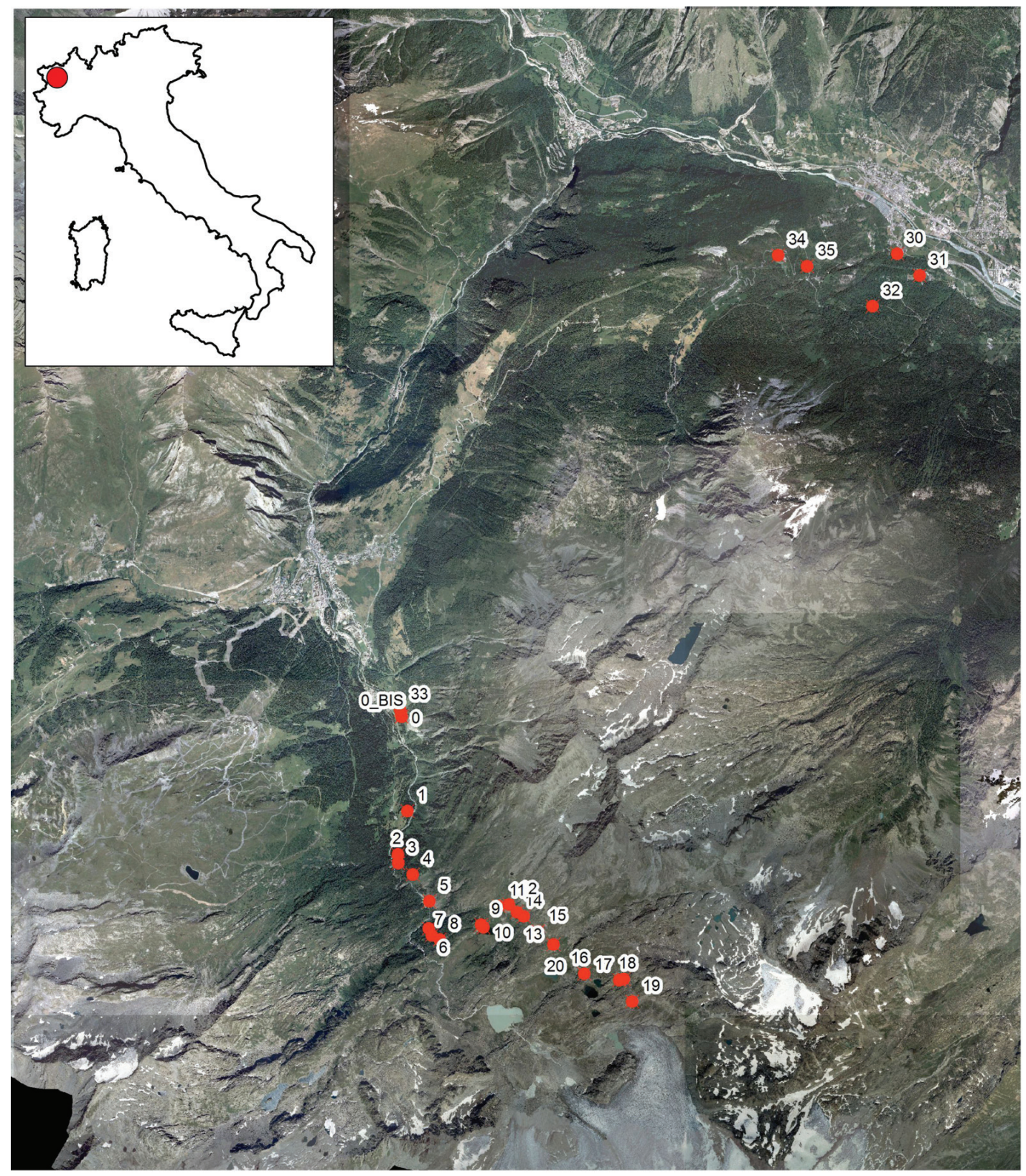

Figure 1. Map showing the location of the study area in north-western Italy and aerial photograph where the 27 sampling sites of the altitudinal training set are represented with red dots

\section{Material and methods}

Modern pollen rain was monitored through the analysis of moss samples at 27 sampling sites from 983 to $2668 \mathrm{~m}$ asl. Three moss samples were taken at each site following the protocol of Cañellas Boltà et al. (2009) and analyzed separately to account for differences in pollen circulation at small scale.
Abundance indexes of vegetation at small and medium scale $(1.8 \mathrm{~m}$ and $10 \mathrm{~m}$-radius around the sampled mosses, respectively) are provided according to the Braun-Blanquet system. At larger scale (>100 m), dominant species were noted.

Precipitation and temperature climate normals (1961-1990 standard period) are estimated by means of a weighted linear regression of the meteorological vari- 
able vs. elevation (Brunetti et al. 2014) starting from a dense and quality-controlled observational dataset.

Altitude, slope, aspect and insolation parameters were calculated in GIS on a 2m-resolution DSM (Digital Surface Model).

Multivariate statistical analysis was applied on modern pollen spectra obtained for the 27 sites and related vegetation data. CCA (Canonical Correspondence Analysis) was first used to check the hypothesis that altitude is the main factor controlling pollen assemblages and vegetation cover along the transect. CCA was then used to explore the relationships between biotic data and abiotic factors (altitude, slope, aspect, curvature, insolation, $\mathrm{T}_{\text {jan }}, \mathrm{T}_{\text {spring, }}$, $\mathrm{T}_{\text {summer }}$ and $\mathrm{P}_{\text {annual }}$ ). DCA (Detrended Correspondence Analysis) was applied to evaluate the relationships between pollen rain and vegetation at small (1.8 m radius) ad larger scale (10 $\mathrm{m}$ radius).

Finally, some observations on the degree of association between pollen and parent taxa along the transect are made, in order to recognize potential indicators of highaltitude ecosystems.

\section{Summary of the results}

We investigated the complex relationships between pollen rain, multi-scale plant cover, modelled climate and terrain parameters. Clustering and Correspondence Analysis highlight a close link between vegetation types and altitude; this factor, along with climate variables, also affects the composition of pollen rain.

High AP (Arboreal Pollen) values are recorded throughout the transect; the pollen representation of anemophilous producers (i.e. Pinus) is always high despite large variations of landscape openness along the transect. Main vegetation types can be recognized based on their pollen images; deciduous forests in the montane belt, $\mathrm{Pi}$ cea-dominated forests between 1500-1780 m asl replaced by Pinus cembra - Larix decidua forests up to $2100 \mathrm{~m}$ asl, open forests and high-altitude shrublands from $2100 \mathrm{~m}$ asl and open vegetation with scattered Larix and Pinus cembra specimens up to $2455 \mathrm{~m}$ asl. Timberline and treeline thresholds are more difficult to detect.

Comparing the presence of parent plants and pollen occurrences, we identify several degrees of association between them, hereafter named according to Cañellas Boltà et al. (2009). Castanea and Olea can be defined as allochtonous taxa (pollen is present throughout the transect but the parent taxa is not found), Larix and Picea are good indicator taxa (similar pattern of pollen occurrence and pollen abundance), Vaccinium and Rhododendron are very good indicator taxa (optimal correspondence between presence of parent taxa and pollen frequencies). Among trees, no correspondence between local occurrence and pollen abundance was found for Abies, that we can define as a non-indicator taxon

\section{The altitudinal training set and the EMPD: a chance for reconstructing quantitative climate parameters from fossil spectra}

Modern pollen rain and associated climate data from the transect were integrated into the EMPD (European Modern Pollen Database; Davis et al. 2013) and used for Holocene climate reconstructions based on the fossil paleoecological record from the Rutor Glacier area. A pollen-inferred temperature record is produced (Badino et al. in prep.) that shows a significant comparison with independent proxies of climate from the high altitude Alps such as the Rhone Glacier length record (Goehring et al. 2012), pollen- and chironomid-inferred T records (Wick et al. 2003; Ilyashuk et al. 2011).

\section{Conclusions}

Altitude controls the distribution of vegetation and influence the composition of modern pollen rain along the $1700 \mathrm{~m}$-high altitudinal transect developed in the western Italian Alps. Terrain and climate parameters explain a large proportion of the total variance within vegetation and pollen data. More factors should be considered for a thorough understanding of the dataset.

Pollen spectra along the transect show compositions related to the different vegetations that originate them, but pollen from different altitudinal belts occurs. From a paleoenvironmental point of view, the occurrence of pollen of plants not pertaining to specific altitudinal belt (i.e. cultivated plants above $2000 \mathrm{~m}$ asl) can be helpful when interpreting fossil pollen spectra and past vegetation extent. The issue of altitudinal transport of pollen due to convective air masses must be carefully considered when using pollen spectra to obtain quantitative climate reconstructions from fossil pollen spectra.

\section{Acknowledgements}

This paper is a contribution to the CNR-IDPA Paleoclimatology Research Line TA.P02.005.001. Part of the activities were supported by the CNR-DTA Project of Interest Nextdata, a national system for the retrieval, storage, access and diffusion of environmental and climate data from mountain and marine areas. 


\section{References}

Brunetti M., Maugeri M., Nanni T., Simolo C. \& Spinoni J., 2014, High-resolution temperature climatology for Italy: interpolation method intercomparison, Int. Journal of Climatology 34: 1278-1296.

Cañellas Boltà N., Rull V., Vigo J. \& Mercadé A., 2009, Modern pollen-vegetation relationships along an altitudinal transect in the western Pyrenees (southwestern Europe), The Holocene 19(8): 1185-1200.

Davis BAS, Zanon M., Collins M., Mauri A., Bakker J., Barboni D., Barthelmes A., Beaudouin C., Birks HJB., Bjune AE. et al., 2013, The European Modern Pollen Database (EMPD) Project, Vegetation History and Archaeobotany 22: 521-530.

Goehring B.M., Vacco D.A., Alley R.B. \& Schaefer J.M., 2012, Holocene dynamics of the Rhone Glacier, Switzerland, deduced from ice flow models and cosmo- genic nuclides, Earth and Planetary Science Letters 351-352: 27-35.

Ilyashuk E.A., Koinig K.A., Heiri O., Ilyashuk B.P. \& Psenner R., 2011, Holocene temperature variations at a high-altitude site in the Eastern Alps: a chironomid record from Schwarzsee ob Sölden, Austria, Quaternary Science Reviews 30(1): 176-191.

Juggins S. \& Birks H.J.B., 2012, Quantitative environmental reconstructions from biological data, [in:] H.J.B. Birks, A.F. Lotter, S. Juggins \& J.P. Smol (Eds.), Tracking environmental change using lake sediments, Data handling and numerical techniques, Springer, Chapter 14: 431-494.

Wick L., van Leeuwen J.F., van der Knaap W.O. \& Lotter A.F., 2003, Holocene vegetation development in the catchment of Sägistalsee (1935 m asl), a small lake in the Swiss Alps, Journal of Paleolimnology 30(3): 261-272. 